\title{
New generation vaccines against bluetongue virus
}

\author{
WIES $Ł A W ~ N I E D B A L S K I$, ANDRZEJ FITZNER
}

Department of Foot and Mouth Disease, National Veterinary Research Institute, Wodna 7, 98-220 Zduńska Wola, Poland

Received 22.08.2017

Accepted 13.11.2017

\section{Niedbalski W., Fitzner A. \\ New generation vaccines against bluetongue virus}

Summary

Over the last three decades, a variety of approaches have been investigated to develop new types of bluetongue virus (BTB) vaccines, ranging from baculovirus-expressed subunit vaccines to live vector vaccines. DNA vaccines against BTV consist of DNA plasmid expressing different BTV proteins after inoculation of the animals. The recombinant viral vector vaccines against BTV are based on recombinant viruses that express desired BTV antigens in the host upon inoculation. Viruses such as vaccinia, modified vaccinia Ancara (MVA), capripox, canarypox, herpes, myxoma and fowlpox viruses have been used as vectors of BTV genes. The reverse genetics (RG) systems for BTV are useful tools for BTV vaccine development. Disabled infectious single-cycle (DISC) vaccines make it possible to restore virus replication and can be used for differentiating infected from vaccinated animals (DIVA). These vaccines are based on the production of a modified virus with a deletion in one or more genes that are essential for virus replication. Another approach for BTV vaccine development using RG is the disabled infectious single-animal (DISA) vaccine, generated by deletion of NS3/NS3a expression. DISC and DISA vaccines can mimic the natural tropism of the virus and can express BTV proteins at the site of infection. Important advantages of these new generation vaccines over the conventional BTV vaccines are their high efficacy as well as the possibility of applying them for DIVA. At present, there are a number of novel laboratoryscale BTV vaccines that could meet vaccine profiles required for different field situations. However, further development and licensing of these vaccine candidates for many BTV serotypes is needed in order to prepare for future BT outbreaks. To date, all novel BTV vaccines described in this paper are still under laboratory testing. They are not available commercially, and the time of their application in the field is still indefinite.

Keywords: bluetongue virus (BTV), experimental vaccines, reverse genetics

Bluetongue (BT) is an economically important, noncontagious disease of domestic and wild ruminants transmitted by Culicoides biting midges (49). It is caused by the bluetongue virus (BTV), which is a member of the genus Orbivirus within the family Reoviridae (25). To date, twenty-seven immunologically distinct serotypes of BTV have been identified worldwide (54). BTV is a small (about $90 \mathrm{~nm}$ in diameter) icosahedral virus with a genome of approximately 19200 base pairs composed of ten linear segments of double-stranded RNA (dsRNA) (26) which encode ten distinct virus proteins (48). Seven of these (VP1 to VP7) are structural components of the icosahedral virus capsid, while three are non-structural proteins (NS1-NS3), which play different key roles during the viral replication cycle (34).

$\mathrm{BT}$ is endemic in most countries in the tropics and sub-tropics between latitudes $40^{\circ} \mathrm{S}$ and $53^{\circ} \mathrm{N}$ of the Americas, Australia, Africa and some regions of Asia (52). In the summer of $2006, \mathrm{BTV}$ crossed latitude $50^{\circ} \mathrm{N}$ for the first time, and BT outbreaks caused by BTV serotype 8 occurred unexpectedly in north-western Europe, whereas in 2007-2008 BTV-8 spread rapidly throughout much of Europe $(38,43)$. The occurrence of BTV-8 in northern Europe caused considerable economic losses, comprising not only direct losses from mortality and reduced production, but also indirect losses due to ensuing bans on the trade of ruminants between BTV-infected and non-infected areas. By 2000, the control strategy of BT in the European Union (EU) was consistent with Directive 92/119/EEC of 17 December 1992 and was essentially based on the stamping-out strategy. This situation was modified rapidly in the autumn of 2000 with Directive 2000/75/EC, as it became obvious that the stamping-out was absolutely inadequate in dealing with vector-borne diseases, such as bluetongue, and the slaughter of all susceptible animals in the entire infected and at-risk areas was not considered an alternative. According to this directive, the primary strategy for BT control should be based on the straightforward control of the transfer of susceptible animals from zones considered infected. Under Commission Decision 2008/655/WE, the strategy for BT control also includes vaccinations aimed at reducing the spread of the virus in the environment and measures to ensure safe movement 
of susceptible animals between affected and free zones. More detailed information on the BT control strategy in Europe is presented in our review article published in 2015 (29).

Vaccination with efficacious vaccines against BTV is one of the most effective approaches to control the disease. However, vaccination can be problematic due to the plurality of BTV serotypes, coupled with apparent serotype-specific immunity of livestock (53). Thus, effective vaccines must potentially be developed for all 27 currently recognized BTV serotypes. In general, vaccines must be efficacious, safe and affordable. BTV vaccination campaigns have contributed to the control of outbreaks in the past (42). Modified live (attenuated) virus (MLV) vaccines were the first vaccines developed for prophylactic immunization of livestock against BTV infection (49) and were routinely used to prevent BT among sheep in the United States, South Africa and Israel, and for compulsory vaccination of cattle and sheep in Italy following the incursion of BTV into that country in 1999 (5). MLV vaccines are relatively cheap and highly effective in preventing clinical BT disease because even a low dose induces both humoral and cellular immune responses (42). However, the use of MLV vaccines is controversial due to disadvantages, such as a significant reduction in milk production in lactating sheep, abortions, stillbirths and teratogenesis in offspring when used in pregnant females (21). Another risk associated with the use of MLV vaccines is their potential of infecting vectors with possible reversion to virulence or reassortment of MLV genes with those of wild-type virus strains (2). Inactivated BTV vaccines were developed in the 1970s and 1980s, but were not commercially available until 2005 , when they were used in the field to vaccinate sheep in Corsica (France) (41). These vaccines have become the preferred type of vaccines in Europe because they do not result in infection and viraemia of vaccinated animals and therefore are inherently safer. If properly manufactured, they cannot be responsible for infection of vectors, reversion to virulence or reassortment with field strains of BTV. However, inactivated BTV vaccines suffer from a relatively slow onset of immunity, as compared to MLV vaccines, and the lack of commercial products for most BTV serotypes $(14,42)$. After the incursion of BTV serotype 8 into north-western Europe in 2006, several inactivated BTV-8 vaccines became commercially available early in 2008 , and vaccination programmes were rapidly initiated throughout most of affected areas. Many inactivated vaccines for sheep and cattle received positive opinion after assessment by the Committee for Medicinal Products for Veterinary Use (CVMP) and were authorized nationally for emergency use. The long-term efficacy of commercially available inactivated vaccines against BTV-8: Bluevac 8 (CZ Veterinaria, Spain), Zulvac 8 (Fort Dodge, the Netherlands), BTVPUR Alsap 8 EU (Merial, France) and Bovilis-BTV-8 (Intervet, the Netherlands), were evaluated in a seroprevalence study and challenge experiments (50). The implementation of BT compulsory vaccination programmes in Europe in spring 2008 resulted in reduction of BTV-8 cases from about 50000 in 2007-2008 to 350 in 2009 and 19 in 2010. The last case of BT caused by BTV8 was reported in May 2011 in northern Sardinia (Italy). However, after a four-year break, on 11 September 2015, an outbreak of BTV-8 was confirmed in central France (40), and by the end of July 2017 a total of 2365 outbreaks of the disease caused by virus serotype 8 were reported throughout France (http://www.oie.int). The conventional BTV vaccines and the history of prophylactic vaccination in Europe have been described in our previous publications $(28,30)$.

Because commercially available MLV and inactivated vaccines against BTV have their specific disadvantages and lack differentiation of infected from vaccinated animals (DIVA), it was necessary to improve them and overcome the limitations of the currently marketed vaccines. Over the last 3 decades, a variety of approaches have been investigated to develop a new type of BTV vaccines for a broad range of BTV serotypes. Different strategies have been explored to develop novel recombinant vaccines for BTV, ranging from baculovirusexpressed subunit vaccines to live virus vector vaccines. Many new experimental vaccines, from non-replicating subunits to replicating reverse genetics-based vaccines, have been developed. Subunit vaccines, as an example of non-replicating vaccines, are based on a single protein or a combination of various proteins used in the same vaccine to elicit protective immune responses in animals, e.g., VP2 structural protein induced virusneutralizing antibodies and protection against a virulent homologous challenge in sheep (15). Roy at al. (37) developed a subunit vaccination strategy based on the expression of BTV proteins, using a recombinant baculovirus system. These proteins were administered in different combinations and doses to sheep, and protection was evaluated against a homologous challenge with virulent BTV-10. A minimal dose of $100 \mu \mathrm{g}$ of VP2 was needed to protect sheep against infection. However, when used in combination with $20 \mu \mathrm{g}$ of VP5, a $50 \mu \mathrm{g}$ dose of VP2 was sufficient to elicit equivalent virusneutralizing antibody titres and to protect sheep against a BTV challenge (37). Another baculovirus and E. coliproduced subunit vaccine containing purified VP2, NS1 and NS2 proteins with an immunostimulating complexbased adjuvant was tested by others (1). Good cellular and humoral immunities were induced after booster vaccination, and this vaccine protected animals against BTV-8 infection three weeks after the booster. The next subunit vaccine was based on two fragments of VP2 (aa 63-47 and 555-956), VP5 lacking the first 100 aa, and VP7 produced in bacteria as soluble fusion-proteins with glutathione S-transferase (27). After immuniza- 
tion with this vaccine of adult mice deficient in type I interferon (IFN) receptor (IFNAR(-/-)), an expression of neutralizing antibodies was found, and the animals survived a homologous challenge without clinical signs after booster vaccination with VP2 domains and VP5. A BTV subunit vaccine based on microspheres of avian reovirus (ARV) muNS-Mi containing BTV-4 VP2, VP7 and NS1 proteins was developed by Marin-Lopez at al. (23). The authors showed that immunization of IFNAR $(-/-)$ mice with these microspheres and without adjuvants generated significant levels of neutralizing antibodies specific to BTV-4. Immunized mice were fully protected against a homologous challenge with a lethal dose of BTV-4 and partially cross-protected against a heterologous challenge with a lethal dose of BTV-1 (23). Another subunit vaccine against BTV-4 was based on VP2 capsid protein expressed alone or fused to the antigen presenting cell homing (APCH) molecule, in the baculovirus insect cell expression system (17). APCH fusion has been demonstrated to be very effective in improving the immune response induced against many different antigens. This subunit vaccine showed a good humoral immune response in cattle and cellular response in IFNAR $(-/-)$ mice enhanced by the fusion of VP2 to the APCH protein.

Virus-like particles (VLPs) an empty BTV particles are also useful as BTV vaccines. VLPs were first developed for BTV-10 (35), and since then this approach has been used to produce VLPs from a variety of BTV serotypes. VLPs have been generated for multiple BTV serotypes, and a cocktail of serotypes BTV-1, 2, 10, 13 and 17 has been tested in vaccination studies and raised specific neutralizing antibodies and a protective response in sheep against homologous infection. Booster vaccination with this cocktail vaccine protected against homologous challenge with all five BTV serotypes at 4 and 14 months post-vaccination and partially against some heterologous serotypes (36). A later study found that VLPs from BTV-8 were able to afford complete protection against a homologous viral infection in sheep (45). Another experiment with baculovirus-expressed antigen showed that co-expression of VP3 and VP7 proteins resulted in the generation of "core-like particles" (CLPs). These CLPs were tested as vaccine candidates, but did not induce protective immunity (42). VLP vaccines are not available commercially, and the reason is probably that the production method is not cost-effective compared with the currently marketed inactivated vaccines. VLPs of BTV were also produced in Nicotiana ben- thamiana plants, using the cowpea mosaic virus-based HyperTrans plant transient expression vector system (46). No clinical manifestations were produced in sheep vaccinated with these VPLs and then challenged with virulent BTV-8 five weeks post-vaccination. Generally, VLP approaches provide opportunities to develop safe and effective vaccines with a potential for DIVA. However, the basic requirement is to produce these vaccines at an affordable price for veterinary application.

DNA vaccines against BTV consist of a DNA plasmid expressing different BTV proteins after the inoculation of animals. Partial protection against BTV-4 infection of mice deficient in IFN receptor was observed after vaccination with plasmids expressing VP2, VP7 and NS1 BTV-4 proteins. Although there was no clinical protection, vireamia was delayed in DNA-BTV immunized mice in comparison with non-immunized animals (7). DNA vaccines can be useful in priming the immune system when used in a heterologous vaccination regime in combination with recombinant viruses as boosting agents $(7,16)$. Advantages of these vaccines are rapid manufacturing, high stability at ambient temperatures and potent induction of Th1 lymphocyte responses. However, the use of DNA vaccines on a global scale is still limited due to their insufficient availability. The recombinant viral vector vaccines are based on recombinant viruses that express desired BTV antigens in the host upon inoculation. Immunity induced by these vaccines depends on the capacity of the viral vector to express BTV genes at high levels within cells of the host. The viral vectors used are attenuated to the host and therefore inherently safe, and the risk of gene segment re-assortment with field BTV strains is limited. The vaccinia, canarypox, capripox and herpes viruses have been tested as potential vectors for BTV vaccination with different levels of success $(3,7,13,51)$ (Tab. 1). Recently, the myxoma virus and fowlpox virus have
Tab. 1. Recombinant viral vector vaccines against BTV tested in sheep and IFNAR $(-/-)$ mice

\begin{tabular}{|c|c|c|c|}
\hline Viral vector & Proteins expressed & $\begin{array}{l}\text { Protection against } \\
\text { homologous } \\
\text { challenge }\end{array}$ & $\begin{array}{l}\text { Protection against } \\
\text { heterologous } \\
\text { challenge }\end{array}$ \\
\hline & & \multicolumn{2}{|c|}{ Sheep } \\
\hline \multirow[t]{2}{*}{$\begin{array}{l}\text { Capripox virus (CPV) } \\
\text { Capripox virus (CPV) } \\
\text { Fowlpox virus (FPV) } \\
\text { Canarypox virus (CNPV) } \\
\text { Myxomavirus (MYXV) } \\
\text { Vaccinia virus (VACV) WR strain } \\
\text { Vaccinia virus (VACV) WR strain } \\
\text { Modified Vaccinia Ankara (MVA) }\end{array}$} & $\begin{array}{l}\text { VP7 BTV-1 } \\
\text { VP2, VP7, NS1, NS3 BTV-2 } \\
\text { VP2, VP5 BTV-1 } \\
\text { VP2, VP5 } \\
\text { VP2 BTV-8 } \\
\text { VP2 } \\
\text { VP2, VP5 BTV-1 } \\
\text { VP2, VP7, NS1 BTV-4 }\end{array}$ & $\begin{array}{l}\text { Not analyzed } \\
\text { Partial } \\
\text { Not analyzed } \\
\text { Complete } \\
\text { Partial } \\
\text { Partial } \\
\text { Partial } \\
\text { Not analyzed }\end{array}$ & $\begin{array}{l}\text { Partial } \\
\text { Not analyzed } \\
\text { Not analyzed } \\
\text { Not analyzed } \\
\text { Not analyzed } \\
\text { Not analyzed } \\
\text { Not analyzed } \\
\text { Partial }\end{array}$ \\
\hline & & \multicolumn{2}{|c|}{ IFNAR (-/-) mice } \\
\hline $\begin{array}{l}\text { Bovine herpes virus } \\
\text { Equine herpes virus } \\
\text { Equine herpes virus } \\
\text { Modified Vaccinia Ankara (MVA) } \\
\text { Modified Vaccinia Ankara (MVA) } \\
\text { Modified Vaccinia Ankara (MVA) } \\
\text { Modified Vaccinia Ankara (MVA) } \\
\text { Modified Vaccinia Ankara (MVA) }\end{array}$ & $\begin{array}{l}\text { VP2 BTV-8 } \\
\text { VP2 BTV-8 } \\
\text { VP2, VP5 BTV-8 } \\
\text { VP2, VP5 BTV-4 } \\
\text { VP2, VP5, VP7 BTV-4 } \\
\text { VP7, NS1 BTV-4 } \\
\text { VP2, VP5, VP7 BTV-8 } \\
\text { VP2 BTV-8 }\end{array}$ & $\begin{array}{l}\text { Partial } \\
\text { No } \\
\text { Partial } \\
\text { Partial } \\
\text { Complete } \\
\text { Partial } \\
\text { Complete } \\
\text { Complete }\end{array}$ & $\begin{array}{l}\text { Not analyzed } \\
\text { Not analyzed } \\
\text { Not analyzed } \\
\text { Not analyzed } \\
\text { Complete } \\
\text { Partial } \\
\text { Not analyzed } \\
\text { Not analyzed }\end{array}$ \\
\hline
\end{tabular}


also been used as BTV vectors $(18,47)$. Several experimental recombinant vaccines have been described, and they clearly have numerous inherent benefits, including a rapid onset of immunity, lack of transmissibility, a potential for DIVA, and even for a polyvalent strategy $(20,31)$. A recombinant vaccinia virus that expressed both VP2 and VP5 of BTV-1 induced variable titres of neutralizing antibodies in sheep and ensured protection against homologous challenge (19). The recombinant modified vaccinia virus Ankara (rMVA) strain has also been used to construct many vectored vaccines expressing different proteins from different BTV serotypes (22). Furthermore, combinations of DNA and rMVA vaccines were used in a heterologous prime boost vaccination strategy (DNA/rMVA), providing protection against BTV in a mouse model system (42). DNA/ rMVA expressing VP2 and VP5 proteins (DNA/rMVA-VP2, -VP5) as well as VP2, VP5, and VP7 proteins (DNA/rMVA-VP2, VP5, VP7) or VP7, NS1 BTV-4 have been described $(6,7)$. It was shown that IFNAR $(-/-)$ mice vaccinated with these DNA/rMVA were protected against lethal challenge with BTV-4, and the vaccination induced neutralizing antibodies and T-cell mediated immunity. Since the massive BTV-8 outbreak in north-western Europe, potential MVA vaccines based on proteins from this serotype have been constructed and tested (16). The efficacy of homologous rMVA/ rMVA and heterologous DNA/rMVA prime-boost vaccination regimes was compared in the IFNAR $(-/-)$ mouse model. These studies used vaccine constructs expressing VP2 alone, VP7 alone or a combination of VP2, VP5 and VP7 from BTV-8 (16). Moreover, a recombinant capripoxvirus expressing VP7 was shown to provide partial protection against heterologous BTV challenge (51), but its development has apparently been discontinued, like that of the recombinant vaccinia BTV vaccine. Finally, a recombinant canarypox virus vaccine co-expressing genes encoding the VP2 and VP3 outer capsid proteins of BTV that induced high level protection in sheep has been developed (3). This vaccine has a major inherent advantage in that the existing competitive ELISA assay would distinguish vaccinated from naturally infected animals. It uses an expression vector that is incorporated in several vaccines already in use in the European Union (EU) and elsewhere, although not in ruminant livestock. In general, vector vaccines expressing BTV VP2 have been the most successful, eliciting protective immune responses in animals (sheep or mice) against homologous challenge, which is consistent with the results obtained from protein-based vaccines. Bovine and equine herpes viruses have also been used to construct recombinant vectored vaccines against BTV-8, achieving partial protection in IFNAR $(-1-)$ mice in vaccination-challenge experiments $(38$, 51) (Tab. 1).

The reverse genetics (RG) system has facilitated the creation of targeted mutant virus strains that elicit protective antibody responses but avoid the undesirable side effects of conventional attenuated vaccines (4). In recent years, a number of new types of BTV vaccines have been developed using reverse genetics of BTV. The serotype-specific replication-deficient BTV vaccines (i.e., disabled infectious single-cycle [DISC] vaccines) make it possible to restore virus replication and can be used for differentiating infected from vaccinated animals (DIVA). These vaccines are based on the production of a modified virus with a deletion in one or more genes that are essential for virus replication. DISC vaccines induce an aborted infection, resulting in the expression of viral proteins at natural sites of infection. To generate a potential DISC vaccine, an RG system was used to rescue defective virus strains with large deletions in an essential BTV gene that encodes the VP6 protein of the internal core (24). In this method, a lethal mutation in one of the genes essential for replication was introduced. A BTV-1 DISC virus was used to construct a defective reassortant by replacing the segments encoding for VP2 and VP5 with those from BTV-8. Vaccination of sheep with a combination of BTV-1 and BTV-8 DISC viruses induced a virus-neutralizing antibody response against each of the BTV serotypes represented in the vaccine, and after challenge with the virulent strains at 21 days post-vaccination, immunized animals showed neither any clinical signs nor viraemia (24). Other DISC vaccines have been generated for BTV serotypes 2, 4, 8, 10 , 13, 21 and 24, and were tested as cocktail vaccines in sheep and cattle. After a booster, all animals had virusneutralizing antibodies against all BTV serotypes used, and the vaccinated animals were protected against clinical signs after challenge with the virulent strains at 21 days post-vaccination with homologous BTV viruses, and no viraemia was detected (8). The high efficacy, safety and genetic stability of BTV DISC vaccines were demonstrated (9). Moreover, the optimal storage conditions for vaccines, including additives, temperature, and desiccation, were determined, and their protective features in animals were confirmed. Groups of sheep vaccinated with a cocktail of vaccines were completely protected from challenge with individual virulent BTV serotypes, both early in the challenge and after 5 months of the challenge, without any clinical disease. There was no interference in protection between the different vaccines (9). Since all viral proteins are present in the DISC vaccine, the possibility to differentiate infected from vaccinated animals is unlikely, especially after revaccinations. The protective dose of DISC vaccines seems to be high, although a single vaccination was protective against challenge, and the minimal protective dose has not yet been determined.

A new approach for BTV vaccine development using RG is the disabled infectious single-animal (DISA) vaccine, generated by deletion of NS3/NS3a expression (11). Because NS3/NS3a expression is not essential for BTV replication in vitro, DISA vaccines can be 
produced on the same cell line as the one used for MLV production. DISA vaccines are based on live-attenuated vaccine virus BTV-6 without expression of dispensable $\mathrm{NS} 3 / \mathrm{NS} 3$ a protein (33). Due to the deletion of virulence determinants (e.g., deletions in the open reading frame of segment 10), these vaccines demonstrate both an avirulent phenotype and significantly reduced viraemia, making them unlikely to be transmitted in the field (12). DISA vaccines for different BTV serotypes can be developed by the exchange of VP2 of BTV serotypes. The exchange of only VP2 induces serotype-specific protection of sheep 3 weeks after a single-dose immunization with a DISA vaccine for serotype 8 and nine weeks after booster vaccination using the same dose $\left(2 \times 10^{5} \mathrm{TCID}_{50}\right)$ of vaccine. These DISA vaccines enable DIVA based on NS3-directed antibodies and sequences of genome segment 10 (10). An important risk of replicating vaccines is an uncontrolled spread of the vaccine virus, and consequently the risk of reversion to virulence by genetic drift or by reassortment with the field virus (genetic shift). However, the possible reversion of DISA vaccines to virulence by the restoration of NS3/NS3a expression through small mutations during genetic drift is excluded by this significant deletion in Seg-10. Regarding reassortment between DISA vaccines and the field virus, the BTV-6 vaccine backbone with wild type Seg-10 is still non-pathogenic (33). This means that genetic shifting by Seg-10 exchange through reassortment is of no risk, and the probability of the mixing of genetic material between DISA vaccines, or between a DISA vaccine and field BTV, resulting in virulent reassortants, is negligible. DISA vaccines do not express immunogenic NS3/NS3a, and an indirect NS3 ELISA could be used for serological DIVA (10). Recently, the optimal route and dose for DISA vaccines in sheep have been studied (32). The results indicate that intramuscular vaccination is the optimal route, and a standardized protective dose of $2 \times 1 \mathrm{ml} 10^{5} \mathrm{TCID}_{50}$ for sheep was established. To summarize, DISA vaccines are non-pathogenic replicating vaccines, they do not cause viraemia, enable DIVA and are highly protective.

In conclusion, a variety of vaccine strategies are potentially available for immunization of ruminant livestock against BTV infection. However, only MLV vaccines and inactivated vaccines have been produced commercially and used widely to prevent the spread of BTV in the environment. In order to overcome the disadvantages of attenuated and inactivated BTV vaccines, many different effective recombinant vaccines have been developed. These vaccines, expressing conserved protective antigens to generate an effective multivalent vaccine, would reduce the number of multiserotype vaccinations required. However, despite the promising level of efficacy and safety of these vaccines, none are commercially available. This is probably due to marketing issues, the voluntary vaccination policy in Europe and the acceptance of endemics in many parts of the world because of the cost of vaccination. As a result, all the new generation BTV vaccines described here are available only at laboratory scale. For preventive vaccination in a BTV-free area at risk, safe and broadly protective vaccines that enable DIVA should be used. This laboratory-scale vaccine for field situations could be an RG-based, serotype inactivated vaccine, since such a vaccine could be quickly available. There are a number of novel laboratory-scale BTV vaccines that could be useful for different field situations. However, further development and licensing of these vaccines for many serotypes is needed to prepare for future BT outbreaks. The experimental vaccines can be useful tools to better understand the immune mechanisms activated in animals to neutralize BTV. Therefore, studies on the new generation vaccines against BTV should be continued and intensified.

\section{References}

1. Anderson J., Hagglund S., Breard E., Comtet L., Lovgren Bengtsson K., Pringle J., Zientara S., Valarcher J. F.: Evaluation of the immunogenicity and experimental subunit vaccine that allows differentiation between infected and vaccinated animals against bluetongue virus serotype 8 in cattle. Clin. Vaccine Immunol. 2013, 20, 1115-1122.

2. Batten C. A., Maan S., Shaw A. E., Maan N. S., Mertens P. P.: A European field strain of bluetongue virus derived from two parental vaccine strains by genome segment reassortment. Virus Res. 2008, 137, 56-63.

3. Boone J. D., Balasuriya U. B., Karaca K., Audonnet J. C., Yao J., He L., Nordgren R., Monaco F., Savini G., Gardner I. A., Maclachlan N. J.: Recombinant canarypox virus vaccine co-expressing genes encoding the VP2 and VP3 outer capsid proteins of bluetongue virus induces high level protection in sheep. Vaccine 2007, 25, 672-678.

4. Boyce M., Celma C. C., Roy P.: Development of reverse genetics systems for bluetongue virus: recovery of infectious virus from synthetic RNA transcripts. J. Virol. 2008, 82, 8339-8348.

5. Calistri P., Giovannini A., Conte A., Nannini D., Santucci U., Patta C., Rolesu S., Caporale V.: Bluetongue in Italy: Part I. Vet. Ital. 2004, 40, 243-251. 6. Calvo-Pinilla E., Navasa N., Anguita J., Ortego J.: Multiserotype protection elicited by a combinatorial prime-boost vaccination strategy against bluetongue virus. PLoS One 2012, 7. doi: 10.1371/journal.pone.0034735.

7. Calvo-Pinilla E., Rodriguez-Calvo T., Sevilla N., Ortego J.: Heterologous prime boost vaccination with DNA and recombinant modified vaccinia virus Ankara protects IFNAR (-/-) mice against lethal bluetongue infection. Vaccine 2009, 28, 437-445.

8. Celma C. C., Boyce M., van Rijn P. A., Eschbaumer M., Wernike K., Hoffmann B., Beer M., Haegeman A., De Clercq K., Roy P.: Rapid generation of replication-deficient monovalent and multivalent vaccines for bluetongue virus: protection against virulent virus challenge in cattle and sheep. J. Virol. 2013, 87, 9856-9864.

9. Celma C. C., Stewart M., Wernike K., Eschbaumer M., Gonzalez-Mollenda L., Breard E., Schulz C., Hoffmann B., Haegeman A., De Clercq K., Zientara S., van Rijn P. A., Beer M., Roy P.: Replication-deficient particles: new insights into the next generation of bluetongue virus vaccines. J. Virol. 2017, 91. doi: 10.1128/JVI.01892-16.

10. Feenstra F., Maris-Veldhuis M., Daus F. J., Tacken M. G., Moormann R. J., van Gennip R. G., van Rijn P. A.: VP2-serotyped live-attenuated bluetongue virus without NS3/NS3a expression provides serotype-specific protection and enables DIVA. Vaccine 2014, 32, 7108-7114

11. Feenstra F., van Gennip R. G., Maris-Veldhuis M., Verheij E., van Rijn P. A.: Bluetongue virus without NS3/NS3a expression is not virulent and protects against virulent bluetongue virus challenge. J. Gen. Virol. 2014, 95, 2019-2029.

12. Feenstra F., van Gennip R. G., van de Water S. G., van Rijn P. A.: RNA elements in open reading frames of the bluetongue virus genome are essential for virus replication. PLoS One 2014, 9. doi: 10.1371/journal.pone.0092377. eCollection 2014.

13. Franceschi V., Capocefalo A., Calvo-Pinilla E., Redaelli M., MucignatCaretta C., Mertens P., Ortego J., Donofrio G.: Immunization of knock-out 
alpha/beta interferon receptor mice against lethal bluetongue infection with a BoHV-4-based vector expressing BTV-8 VP2 antigen. Vaccine 2011, 29, 3074-3082.

14. Gethmann J., Huttner K., Heyne H., Probst C., Ziller M., Beer M., Hoffmann B., Mettenleiter T. C., Conraths F. J.: Comparative study of three inactivated BTV-8 vaccines in sheep and cattle under field conditions. Vaccine 2009, 27 , 4118-4126.

15. Huismans H., van der Walt N. T., Cloete M., Erasmus B. J.: Isolation of a capsid protein of a bluetongue virus that induces a protective immune response in sheep. Virology 1987, 157, 172-179.

16. Jabbar T. K., Calvo-Pinilla E., Mateos F., Gubbins S., Bin-Tarif A., BachanekBankowska K., Alpar O., Ortego J., Takamatsu H. H., Mertens P. P., CastilloOlivares $J$. : Protection of IFNAR (-/-) mice against bluetongue virus serotype 8 by heterologous (DNA/rMVA) and homologous (rMVA/rMVA) vaccination, expressing outer-capsid protein VP2. PLoS One 2013, 8. doi: 10.137/journal. pone. 0060574

17. Legisa D. M., Perez Aguirreburualde M. S., Gonzalez F. N., Marin-Lopez A., Ruitz V., Wigdorovitz A., Martinez-Escribano J. A., Ortego J., Dus Santos $M$. $J$.: An experimental subunit vaccine based on bluetongue virus 4 VP2 protein fused to an antigen-presenting cells single chain antibody elicits cellular and humoral immune responses in cattle, guinea pigs and $\operatorname{IFNAR}(-/-)$ mice. Vaccine 2015, 33, 2614-2619.

18. Li J., Yang T., Xu Q., Sun E., Feng Y., Lv S., Zhang Q., Wang H., Wu D.: DNA vaccine prime and recombinant FPV vaccine boost: an important candidate immunization strategy to control bluetongue virus type 1. Appl. Microbiol. Biotechnol. 2015, 99, 8643-8652.

19. Lobato Z. I., Coupar B. E., Gray C. P., Lunt R., Andrew M. E.: Antibody responses and protective immunity to recombinant vaccinia virus-expressed bluetongue virus antigens. Vet. Immunol. Immunopathol. 1997, 59, 293-309.

20. Maclachlan N. J., Mayo C. E.: Potential strategies for control of bluetongue, a global emerging, Culicoides-transmitted viral disease of ruminant livestock and wildlife. Antiviral Res. 2013, 99, 79-90.

21. Maclachlan N. J., Drew C. P., Darpel K. E., Worwa G.: The pathology and pathogenesis of bluetongue. J. Comp. Pathol. 2009, 141, 1-16.

22. Marin-Lopez A., Ortego J.: Generation of recombinant modified vaccinia virus Ankara encoding VP2, NS1, and VP7 proteins of bluetongue virus. Methods Mol. Biol. 2016, 1349, 137-150.

23. Marin-Lopez A., Otero-Romero I., de la Poza F., Menaya-Vargas R., CalvoPinilla E., Benavente J., Martinez-Costas J. M., Ortego J.: VP2, VP7, and NS1 proteins of bluetongue virus targeted in avian reovirus muNS-Mi microspheres elicit a protective immune response in $\operatorname{IFNAR}(-/-)$ mice. Antiviral Res. 2014 , 110, 42-51.

24. Matsuo E., Celma C. C., Boyce M., Viarouge C., Sailleau C., Dubois E., Breard E., Thiery R., Zientara S., Roy P.: Generation of replication-defective virus-based vaccines that confer full protection in sheep against virulent bluetongue virus challenge. J. Virol. 2011, 85, 10213-10221.

25. Mertens P. P., Maan S., Samuel A., Attoui H.: Orbivirus, Reoviridae, [in:] Fauquet C. M., Mayo M. A., Maniloff J., Desselberger U., Ball L. A. (eds): Virus taxonomy: VIIIth report of the ICTV, Elsevier/Academic Press, London 2005, p. 466-483.

26. Mertens P. P., Diprose J.: The bluetongue virus core: a nano-scale transcription machine. Virus Res. 2004, 101, 29-43.

27. Mohd Jaafar F., Belhouchet M., Vitour D., Adam M., Breard E., Zientara S., Mertens P. P., Attoui H.: Immunisation with bacterial expressed VP2 and VP5 of bluetongue virus (BTV) protect alpha/beta interferon-receptor knock-out (IFNAR(-/-)) mice from homologous lethal challenge. Vaccine 2014, 32, 4059-4067.

28. Niedbalski $W$. B Bluetongue vaccines in Europe. Pol. J. Vet. Sci. 2011, 14, 299-304.

29. Niedbalski $W$.: Strategia zwalczania choroby niebieskiego języka w Europie. Med. Weter. 2015, 71, 206-2010.

30. Niedbalski W., Kęsy A.: Choroba niebieskiego języka - szczepienia profilaktyczne w Europie. Med. Weter. 2009, 65, 79-83.

31. Noad R., Roy P.: Bluetongue vaccines. Vaccine 2009, 27, Suppl. 4, D86-89.

32. Rijn P. A. van., Daus F. J., Maris-Veldhuis M. A., Feenstra F., van Gennip $R$. G.: Bluetongue disabled infectious single animal (DISA) vaccine: studies on the optimal route and dose in sheep. Vaccine 2017, 35, 231-237.

33. Rijn P. A., van., Geurts Y., van $\operatorname{der}$ Spek A. N., Veldman D., van Gennip R. G.: Bluetongue virus serotype 6 in Europe in 2008 - emergence and disappearance of an unexpected non-virulent BTV. Vet. Microbiol. 2012, 158, 23-32.
34. Roy P.: Bluetongue virus proteins and particles and their role in virus entry, assembly, and release. Adv. Virus Res. 2005, 64, 69-123.

35. Roy P.: Use of baculovirus expression vector: development of diagnostic reagents, vaccines and morphological counterparts of bluetongue virus. FEMS Microbiol. Immunol. 1990, 2, 223-234.

36. Roy P., Bishop D. H., LeBlois H., Erasmus B. J.: Long-lasting protection of sheep against bluetongue challenge after vaccination with virus-like particles: evidence for homologous and partial heterologous protection. Vaccine 1994, $12,805-811$

37. Roy P., Boyce M., Noad R.: Prospects for improved bluetongue vaccines. Nat. Rev. Microbiol. 2009, 7, 120-128.

38. Saegerman C., Berkvens D., Mellor P. S.: Bluetongue epidemiology in the European Union. Emerg. Infect. Dis. 2008, 14, 539-544.

39. Said A., Damiani A., Ma G., Kalthoff D., Beer M., Osterrieder N.: An equine herpesvirus 1 (EHV-1) vectored $\mathrm{H} 1$ vaccine protects against challenge with swine-origin influenza virus H1N1. Vet. Microbiol. Infect. Dis. 2011, 154, 113-123.

40. Sailleau C., Breard E., Viarouge C., Vitour D., Romey A., Garnier A., Fablet A., Lowenski S., Gorna K., Caignard G., Pagneux C., Zientara S.: Re-emergence of bluetongue virus serotype 8 in France, 2015.Transbound. Emerg. Dis. 2017, 64, 998-1000.

41. Savini G., Hamers C., Conte A., Miglaccio P., Bonfini B., Teodori L., Di Ventura M., Hudelet P., Schumacher C., Caporale V.: Assessment of efficacy of a bivalent BTV-2 and BTV-4 inactivated vaccine by vaccination and challenge in cattle. Vet. Microbiol. 2009, 133, 1-8.

42. Savini G., MacLachlan N. J., Sanchez-Vizcaino J. M., Zientara S.: Vaccines against bluetongue in Europe. Comp. Immunol. Microbiol. Infect. Dis. 2008, 31, 101-120.

43. Sperlova A., Zendulkova D.: Bluetongue: a review. Vet. Med. 2011, 56, 430$-452$.

44. Stewart M., Dovas C. I., Chatzinasiou E., Athmaram T. N., Papanastassopoulou M., Papadopoulos O., Roy P.: Protective efficacy of bluetongue virus-like and subvirus-like particles in sheep: presence of the serotype-specific VP2, independent of its geographic lineage, is essential for protection. Vaccine 2012, 30, 2131-2139.

45. Stewart M., Dubois E., Sailleau C., Breard E., Viarouge C., Desprat A., Thiery $R$., Zientara $S$., Roy $P$.: Bluetongue virus serotype 8 virus-like particles protect sheep against virulent infection as a single or multi-serotype cocktail immunogen. Vaccine 2013, 31, 553-558.

46. Thuenemann E. C., Meyers A. E., Verwey J., Rybicki E. P., Lomonossoff G. P.: A method for rapid production of heteromultimeric protein complexes in plants: assembly of protective bluetongue virus-like particles. Plant Biotechnol. J. 2013, 11, 839-846.

47. Top S., Foucras G., Deplanche M., Rives G., CalvalidoJ., Comtet L., Bertagnoli S., Meyer $G$.: Myxomavirus as a vector for the immunization of sheep: protection study against challenge with bluetongue virus. Vaccine 2012, 30, 1609-1616.

48. Verwoerd D. W.: History of Orbivirus research in South Africa. J. S. Afr. Vet. Assoc. 2012, 83:532. doi: 10.4102/jsava.v83i1.532

49. Verwoerd D. W., Erasmus B. J.: Bluetongue, [in]: Tustin R. C., Coetzer J. A. (eds): Infectious disease of livestock. Oxford University Press, Cape Town 2004, p. 1201-1220.

50. Wackerlin R., Eschbaumer M., Konig P., Hoffmann B., Beer M.: Evaluation of humoral response and protective efficacy of three inactivated vaccines against bluetongue virus serotype 8 one year after vaccination of sheep and cattle. Vaccine 2010, 28, 4348-4355.

51. Wade-Evans A. M., Romero C. H., Mellor P., Takamatsu H., Anderson J., Thevasagayam J., Fleming M. J., Mertens P. P., Black D. N.: Expression of the major core structural protein (VP7) of bluetongue virus by a recombinant capripox virus, provides partial protection of sheep against a virulent heterotyping bluetongue virus challenge. Virology 1996, 220, 227-231.

52. Walton T. E.: The history of bluetongue and a current global overview. Vet. Ital. 2004, 40, 31-38.

53. Zientara S., MacLachlan N. J., Calistri P., Sanchez-Vizcaino J. M., Savini G.: Bluetongue vaccination in Europe. Expert Rev. Vaccines 2010, 9, 989-991.

54.Zientara S., Sailleau C., Viarouge C., Höper D., Beer M., Jenckel M., Hoffmann B., Romey A., Bakkali-Kassimi L., Fablet A., Vitour D., Breard E.: Novel bluetongue virus in goats, Corsica, France, 2014. Emerg. Infect. Dis. 2014, 20, 2123-2125.

Corresponding author: dr hab. Wiesław Niedbalski, Assoc. Prof., Wodna 7, 98-220 Zduńska Wola, Poland; e-mail: wieslaw.niedbalski@piwzp.pl 